\title{
Prevalence and Partern of Early Adverse Reactions in Cancer Patients Receiving Chemotherapy at Ocean Road Cancer Institute
}

\author{
Theophylly Ludovick Mushi ${ }^{1 *}$ and Roger L Mbise ${ }^{2}$ \\ ${ }^{1}$ Medical Doctor, Bachelor of Medicine and Bachelor of Surgery, Tanzania \\ ${ }^{2}$ Professor and Head of Department, Department of Pediatrics and Child Health, Tanzania
}

*Corresponding author: Theophylly Ludovick Mushi, Medical Doctor, Bachelor of Medicine and Bachelor of Surgery, Tanzania

\begin{tabular}{|c|c|}
\hline ARTICLE INFO & ABSTRACT \\
\hline $\begin{array}{l}\text { Received: 蔧August 02, } 2019 \\
\text { Published: 蔧 August 09, } 2019\end{array}$ & $\begin{array}{l}\text { The major challenge in the management of cancer patients who are receiving } \\
\text { chemotherapy regimens is the manifestation of adverse drug reactions which may be very } \\
\text { unpleasant. The objective of this study was to determine the prevalence and pattern of }\end{array}$ \\
\hline $\begin{array}{l}\text { Citation: Theophylly Ludovick Mushi, } \\
\text { Roger L Mbise. Prevalence and Partern } \\
\text { of Early Adverse Reactions in Cancer } \\
\text { Patients Receiving Chemotherapy at } \\
\text { Ocean Road Cancer Institute. Biomed } \\
\text { J Sci \& Tech Res 20(3)-2019. BJSTR. } \\
\text { MS.ID.003451. }\end{array}$ & $\begin{array}{l}\text { Cancer Institute. This was a descriptive cross-sectional hospital-based study on patients } \\
\text { who were on chemotherapy, either alone or in combination with radiation and/ or surgery. } \\
\text { SPSS for descriptive purposes was used to analyze the data. A total of } 80 \text { patients were } \\
\text { recruited for the study, } 64(80 \%) \text { inpatients and } 16(20 \%) \text { outpatients. Seventy-six }(95 \%) \\
\text { out the } 80 \text { patients developed adverse reactions. The early manifestation of adverse } \\
\text { drug reactions which occurred within } 3 \text { days of starting chemotherapy were: fatigue in } \\
66(82.5 \%) \text {, nausea in } 58(72.5 \%) \text {, loss of appetite in } 58(72.5 \%) \text { and mouth sores in } 28\end{array}$ \\
\hline $\begin{array}{l}\text { Keywords: Cancer; Chemotherapy; } \\
\text { ADRs }\end{array}$ & $\begin{array}{l}(35 \%) \text { of the patients. Those after } 2-3 \text { weeks included hair loss in } 39(48.8 \%) \text { and lower } \\
\text { abdominal pain in } 52(65 \%) \text { of the patients, and } 50(62.5 \%) \text { of the patients developed } \\
\text { anemia. Most of the patients on chemotherapy for cancer developed adverse reactions, } \\
\text { which are variable in type and severity. The early detection of these ADRs helped to modify } \\
\text { the drug dosage or the drug regimen. }\end{array}$ \\
\hline
\end{tabular}

\section{Introduction}

Cancer is a global problem accounting for almost $13 \%$ of all deaths worldwide. By 2020 it is estimated that there will be 17 million of new cancer cases every year, $60 \%$ of whom will be in developing countries where management of cancer patients is still a major challenge. Adverse reactions (ADRs) constitute a major clinical problem in terms of human suffering and increases healthcare costs [1]. The World Health Organization (WHO) defines an ADR as "any response to a drug which is noxious, unintended and occurs at doses used in man for prophylaxis, diagnosis or therapy" [2]. Chemotherapy is employed as part of a multimodal approach to treatment of many tumuors. The dosage, regime and method of administration of some anticancer drugs greatly affect their efficacy and toxicity [3]. The commonly used anticancer drugs at Ocean Road Cancer Institute (ORCI) in Tanzania are alkylating agents, cytotoxic antibiotics, antimetabolites, vinca alkaloids and several other anti-neoplastic drugs [4]. Chemotherapy is used for curative intent in cancer to prolong life or to palliate symptoms. These cytotoxic drugs work by impairing mitosis of fast dividing cells, causing damage to DNA and inhibition of cellular machinery involved in cell division [5]. They affect both cancer and healthy cells (i.e. those of bone marrow, digestive tract and hair follicles), thus leading to undesirable effects.

It has been estimated that about one-third of cancer patients on chemotherapy develop adverse reactions, the exact incidence of adverse reactions is not known [6]. Today, an increasingly important issue in oncology is to ensure the quality of life, (QoL) in cancer patients [7]. In 2012, ORCI Tanzania provided care for 5,500 new cancer patients and also provides over 10,000 follow-up cancer cases. About $60 \%$ of the patients with cancer in Tanzania receive chemotherapy every year and the major cost they incur is of treating adverse effects. The Tanzania Demographic and Health Survey 2012 Report showed that Tanzania had a population 
of $44,928,923$ million people with an estimated 21,180 cancer cases8. The number of cancer patients is increasing every year and resources to manage this large burden are limited. For example, there was only one cancer hospital (ORCI) and only 19 medical oncologists for the whole country by the end of 2014. The limited resources for managing patients with cancer pose a great challenge in the clinical practice considering the duration of hospital stay, outpatient treatment and the ratio between oncologists and number of patients at Ocean Road Cancer Institute. It is clear that most of patients do not receive adequate treatment and follow up. Chemotherapy is a major modality of treatment and is associated with adverse reactions. Since many patients have to be treated as outpatients and there is great need for patients and health care workers to know the ADRs of the drug used and how these can be prevented. This study was undertaken to determine the prevalence and pattern of early adverse reactions in cancer patients receiving chemotherapy at Ocean Road Cancer Institute, a tertiary care hospital in Tanzania. The specific objectives included to determine; the sociodemographic data of the patients, types of cancer and chemotherapeutic agent(s) used, the pattern(s) adverse reactions developed, and lastly, to determine treatment and treatment outcomes of chemotherapy ADRs in patients at ORCI.

\section{Material and Methods}

This study was conducted at ORCI in 2014 and reviewed on 2019. The study population included patients who were on

\section{The Most Diagnosed Cancer in ORCI and Chemotherapy} Regimens Used in their Management

Table 1 shows the most prevalent cancer(s) diagnosed at Ocean Road Cancer Institute and their respective chemotherapeutic chemotherapy either alone or in combination with radiotherapy and/ or surgery, inpatients and outpatients. Data collection was done by using a structured questionnaire and analysis was done by SPSS for descriptive statistics

\section{Results}

A total of 80 patients on treatment for cancer were recruited for the study at ORCI, which is the only cancer treatment hospital in Tanzania. The total number of patients comprised 33 (41.2\%) males and $47(58.8 \%)$ female $64(80 \%)$, inpatients and 16 (20\%) were outpatients. Seventy-six (95\%) out of the 80 patients developed adverse reactions. Sixty (75\%) of the patients were married and $20(25 \%)$ were single. Those who had no formal education were $26(32 \%)$ and those who were literate were 54 (68\%). The age distribution of the patients is shown in Figure 1. Patients below 20 years were 2 (2.5\%), 21-40 years were 21 (26.3\%), 41-60 years were $30(37.5 \%)$ and those $\geq 61$ were 27 (33.8\%).

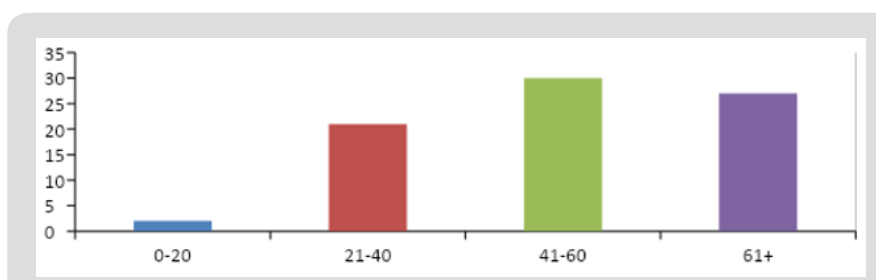

Figure 1: Flowering Iranian borage, Echium amoenum Fisch. \& CA Mey.

regimens. The cancer of the cervix is the commonest, occurring in $19(23.6 \%)$ of the patients, followed by cancer of breast in 17 (21.8\%), lymphoma 16 (20\%), etc. in that order.

Table 1: The prevalence and distribution pattern of diagnosed cancers and drug regimen

\begin{tabular}{|c|c|c|c|}
\hline Cancer & & $\%$ & Chemo- Drug \\
\hline CERVIX & 19 & 23.6 & $\begin{array}{l}\text { Doxorubicin, Cisplastin, Gemcitabine, Vincristine, Paclitaxel, mitomycin, cyclo- } \\
\text { phosphamide (CPS), }\end{array}$ \\
\hline BREAST & 18 & 21.8 & Doxorubicin, MTX, Paclitaxel, Gemcitabine, 5FU, Dercotaxel, epirubicin \\
\hline LYMPHOMA & 16 & 20 & CPS, Procarbazine, Paclitaxel, Doxo-, Gemcitabine, Darcaba \\
\hline OESOPHAGUS & 10 & 10.9 & 5FU, CPS, Doxo-,Bleomycin,Vinblastine \\
\hline NPC & 7 & 7.3 & Epirubicin, 5FU, mitomycin, Darcabazine, vincristine \\
\hline KAPOSIS SARCOMA & 5 & 5.45 & Bleomycin, Vincristine, Adriamycin, doxorubicin, vinblastine \\
\hline BLADDER, & 4 & 3.6 & Cisplastin, Doxorubicin, Gemcitabine \\
\hline \multicolumn{4}{|l|}{ PROSTATE } \\
\hline BONE TUMORS & & & Doxorubicin, Cisplastin \\
\hline \multirow[t]{2}{*}{ MELANOMA } & 1 & 1.8 & Darcabazine, vinblastine, cisplastin \\
\hline & 1 & 1.8 & \\
\hline LIPOMA & 1 & 1.8 & CHOP \\
\hline
\end{tabular}


The Prevalence of Adverse Reactions to Chemotherapy (Table 2)

Table 2: Prevalence/pattern of adverse reactions in cancer patients receiving chemotherapy.

\begin{tabular}{|c|c|c|c|c|c|}
\hline \multirow{2}{*}{ ADR } & & Sex & & \multirow{2}{*}{ Total } & $\%$ \\
\cline { 2 - 5 } & Male & & Female & & \\
\hline Fatigue & 27 & & 39 & 66 & $82.5 \%$ \\
\hline Nausea & 25 & & 33 & 58 & $72.5 \%$ \\
\hline Vomiting & 21 & & 27 & 48 & $60 \%$ \\
\hline $\begin{array}{c}\text { Appetite Loss } \\
\text { Sores (Mouth, }\end{array}$ & 12 & & 16 & 28 & $36 \%$ \\
\hline throat) & 15 & & 24 & 39 & $48.75 \%$ \\
\hline Alopecia & 22 & & 30 & 52 & $65 \%$ \\
\hline Pain & 19 & & 31 & 50 & $62.5 \%$ \\
\hline Anemia & & & & $58 \%$ & \\
\hline
\end{tabular}

Fatigue in $66(82.5 \%)$, loss of appetite in 58 (72.5\%), the progressive loss of appetite leads to inadequate food intake with consequent muscle wasting. Nausea in $58(72.5 \%)$ and Vomiting in $48(60 \%)$. The sores occurred in $28(35 \%)$ of the patients, and they mainly involved the mouth, lip and throat. They were associated with pain and interfered with eating and talking. Hair loss was reported by 39 (48.8\%) of the patients. Some the patents reported re-growth of their hair in six to 12 months after stopping chemotherapy. Anaemia was reported in 50 (62.5\%) of the patients, 19 (23.8\%) males and 31 (38.8\%) females.

\section{The Frequency Distribution and Duration of Onset of ADRS in Cancer Patients Receiving Chemotherapy at ORCI:}

Figure 2 shows the frequency distribution of ADRs and time which elapsed from the start of chemotherapy to the onset of the ADRs. One (1.25\%) of the patients developed ADRs a minute after being given the first dose of docetaxel solution. This was a 37 years old female diagnosed with cancer of the breast. She developed sudden onset of chest tightness, difficulty in breathing and coughing. The injection was immediately stopped; the patient was given normal saline and the adverse reactions resolved. Therefore, the cytotoxic infusion was resumed until the required dose had been given. Other adverse reactions developed from the 3rd day, and included: fatigue, diarrhea, nausea, vomiting and loss of appetite. Sixty-five (80\%) the patients developed ADRs within 0-2 weeks, 9 (11.25\%) after 3 to 4 weeks, and the ADRs included: sores, numbness and discoloration of the skin. Lastly, 4 (5\%) of the patients on chemotherapy did not develop ADRs.

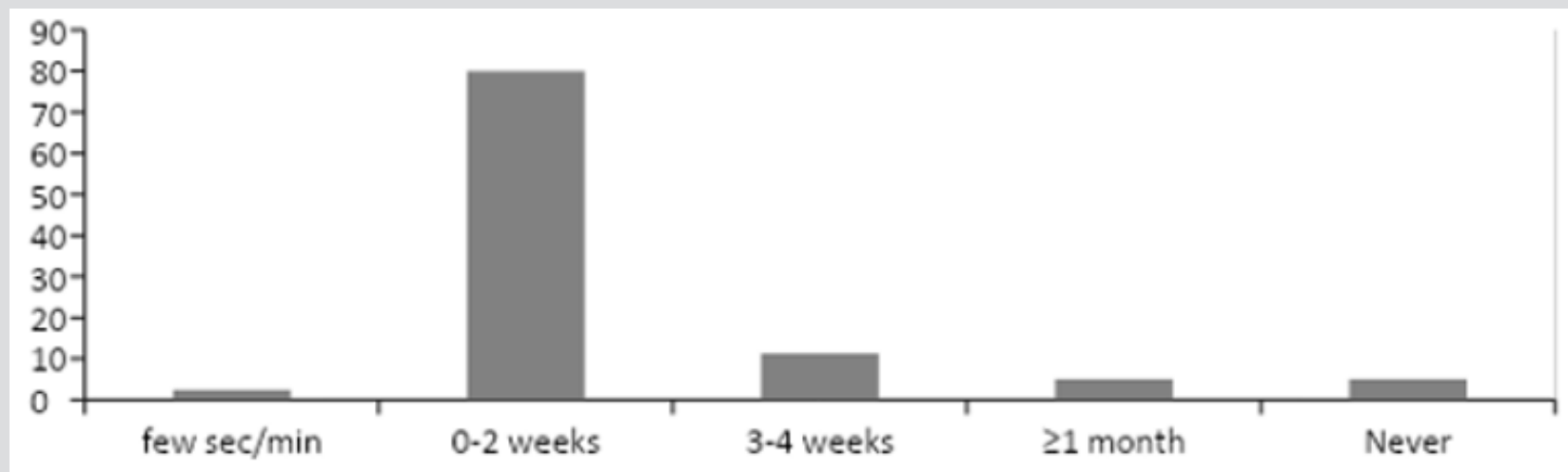

Figure 2: Time at which ADRs were reported after starting chemotherapy.

\section{Treatment of Side Effects and Outcome}

Thirty (40\%) of the patients on chemotherapy were given injection emeset (ondesartan) as antiemetic, and all of them did not report any further vomiting. Twenty-two $(27.5 \%)$ of the patients on chemotherapy were given metoclopramide and did not report anorexia anymore. Patients who had previous history or were likely to develop abnormal respiratory symptoms were given Prednisolone to prevent occurrence of adverse effects. IV dexamethasone injection was given to all patients who developed allergic reactions after chemotherapy, and this gave positive results. Other patients were given leucovorin to prevent harmful effect of Methotrexate (MTX).

\section{Discussion}

The type and severity of adverse reactions in cancer patients who are receiving chemotherapy developed depending on the type of the drugs, the dosage, and how the drugs were given. Fatigue which was reported in $82.5 \%$ ) of the patients affects mental, physical and emotional wellbeing of the patients and was caused by anaemia resulting from bone marrow suppression by chemotherapy drugs. When the effect of the drug is diminished this condition gradually resolved. These findings are similar to those reported elsewhere [8]. Nausea was reported by $72.5 \%$ and vomiting by $60 \%$ of the patients respectively. A similar study reported that only $20 \%$ of patients experienced nausea before any one chemothera- 
py cycle, and that up to $30 \%$ reported this anticipatory, learned, or psychological nausea by the fourth chemotherapy cycle; repeated exposure to chemotherapy was associated with an increased risk of developing nausea and vomiting [9]. Loss of appetite was reported by $72 \%$ of the patients and was associated by weight loss. A similar study reported that $80 \%$ of the patients with advanced cancers had nausea and weight loss [10]. Sores developed due to reactions of chemotherapy regimens on cells overlying the gastrointestinal tract. In a similar study, approximately $51 \%$ of the patients reported to have developed mouth sores. The severity the mouth sores was correlated with fatigue [11]. Hair loss is the most prominent ADR after 6 weeks cancer chemotherapy. However, re-growth occurs within 3 months after cessation of chemotherapy and hair growth rate returns to baseline value. Tamoxifen did not affect hair growth [12].

\section{Conclusions}

Most of the patients on chemotherapy for cancer develop adverse reaction, which are variable in type and severity. The early detection of these ADRs helps to modify the doses or the drug regimen to minimize hazardous effects. The provision of prophylaxis against some of the ADRs reduces the occurrence of adverse reactions and allows completion of the required chemotherapeutic regimen.

\section{Recommendations}

a) Patient(s) and healthcare workers education on the ADR of chemotherapy

b) Proper management and follow up of cancer patients who are receiving chemotherapy to ensure compliance and therefore good treatment outcome.

\section{ISSN: 2574-1241}

DOI: 10.26717/BJSTR.2019.20.003451

Theophylly Ludovick Mushi. Biomed J Sci \& Tech Res

CC) This work is licensed under Creative

Submission Link: https://biomedres.us/submit-manuscript.php

\section{References}

1. Nerurkar RP, Nadkar MY, Bichile SK (1998) Need for monitoring adverse drug reactions. J Assoc. Physicians India 46: 673-674.

2. Lee A, Thomas SHL (2003) Adverse Drug Reactions in Clinical Pharmacy and Therapeutics. In Lee A, Thomas SHL (Eds.), ( $3^{\text {rd }}$ edn.). Spain: Churchill Livingstone p. 33-34.

3. Balmer CM, Valley AW, Iannucci A (2005) Cancer Treatment and Chemotherapy In: Pharmacotherapy: A Pathophysiologic Approach. McGraw-Hill, Inc 2279.

4. Rahman MH (2006) Drugs used in malignant disease and immunosuppression. In: Bangladesh national Formulary. Directorate of Drug Administration, Dhaka 14: 400-430.

5. Sneegdha P, Razia S, Rebeka S, Mohammad A, Mohammad AK (2009) Pattern of Adverse Drug Reactions Due to Cancer Chemotherapy in Tertiary Care Teaching Hospital in Bangladesh; Hasnat Dhaka Univ. J. Pharm. Sci 8(1): 11-16.

6. Thatcher N, Hopwood P, Anderson H (1997) Improving quality of life in patients with non-small cell lung cancer: research experience with gemcitabine. Eur J Cancer 33: 8.

7. (2012) Tanzania Demographic and Health Survey Report.

8. Vogelzang NJ, Breitbart W, Cella D (1997) Patient, Caregiver and oncologist perception of cancer- related fatigue. Semin Hematol 32: 4-12.

9. Charles K, Mohamedtaki A, Tejan, Anita RP (2014) Anticipatory nausea and vomiting due to chemotherapy.

10. Loss of appetite and weight loss, a very common and difficult problem for cancer patients.

11. Brown CG, Mc Guire DB, Peterson DE, Beck SL, Dudley WN Mooney (2009) The experience of sore mouth and associated symptoms in patients with cancer receiving outpatient chemotherapy 34(4): 413428.

12. Carrim ZI, Kajaige J, Bowman RJ, Lavy TE, Scanlan P (2012) Royal Hospital for sick children, Lanak. First year experience of chemotherapy for advanced retinoblastoma in Tanzania. Disease profile outcome and challenge in 2008. J Pediatr Ophthalmol Strabismus 49(3): 176-183.

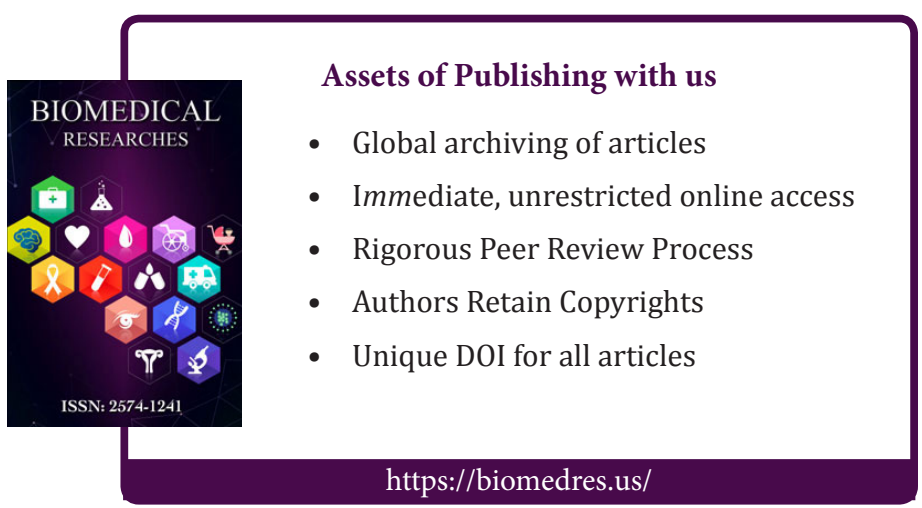

